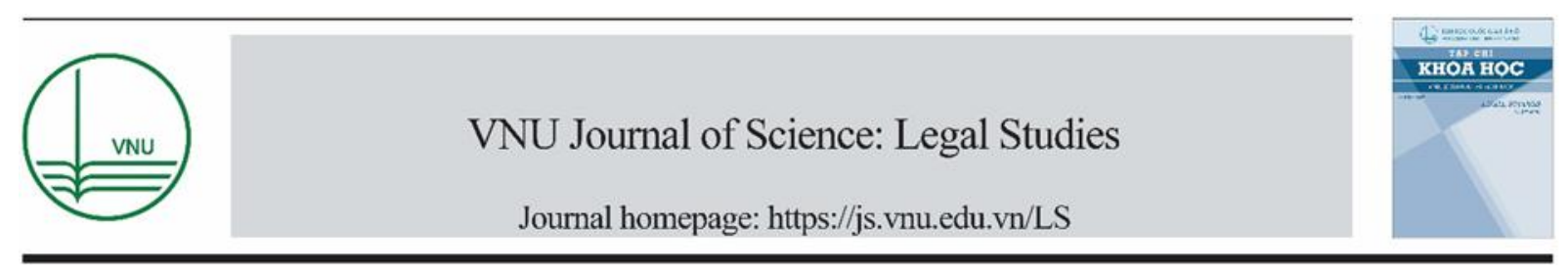

Review Article

\title{
Consumer Disadvantaged Rights Protection in the Vietnamese and Taiwanese Laws
}

\author{
Nguyen Trong Diep ${ }^{1, *}$, Nguyen Tien Dat ${ }^{2}$ \\ ${ }^{1}$ School of Law, Vietnam National University Hanoi, 144 Xuan Thuy, Cau Giay, Hanoi, Vietnam \\ ${ }^{2}$ Academy of Policy and Development Lane 7 Ton That Thuyet, Cau Giay, Hanoi, Vietnam
}

Received 11 April 2019

Revised 22 May 2019; Accepted 24 June 2019

\begin{abstract}
In a competitive market, consumers are protected by law to avoid the risks and damages resulting from the asymmetry of position between the seller and the consumer, or the concept of "persons disadvantaged". Taiwan (China) and Vietnam's consumer protection laws create all the necessary legal foundations that consumers can use during the consumption process and even in the event of damage, risk. The legislative experiences and the results of the implementation of regulations in Taiwan are also important lessons for Vietnam in the development of consumer law.
\end{abstract}

Keywords: Taiwan, consumer law, disadvantaged, consumer protection.

\footnotetext{
* Corresponding author.

E-mail address: dieptrongnguyenvnu@gmail.com

https://doi.org/10.25073/2588-1167/vnuls.4220
} 


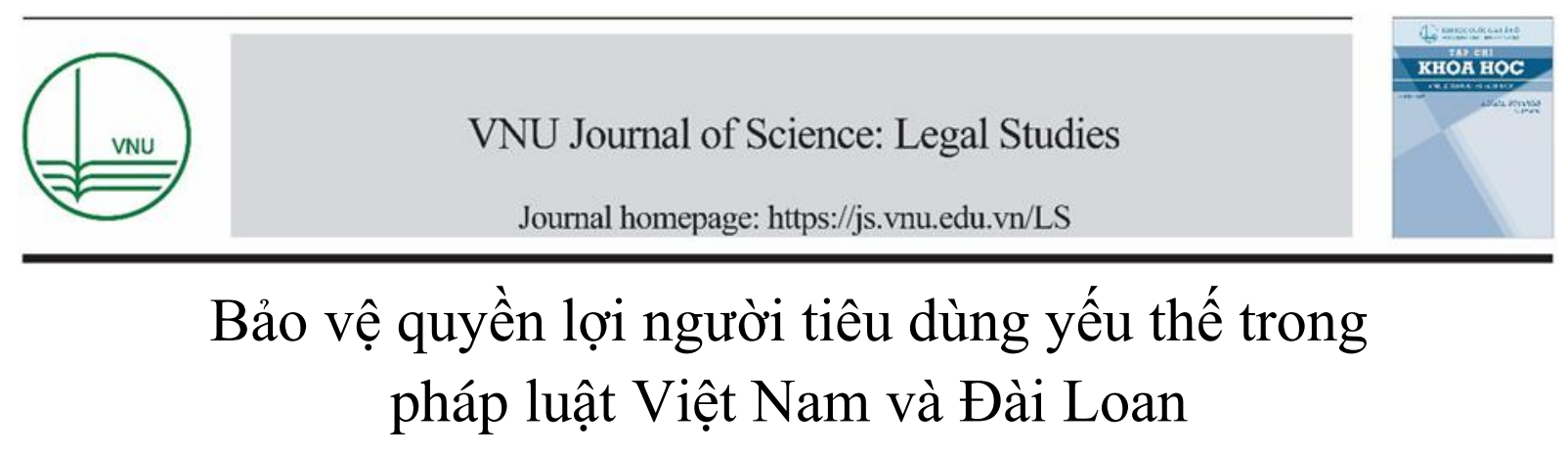

\author{
Nguyễn Trọng Điệp ${ }^{1, *}$, Nguyễn Tiến Đạt ${ }^{2}$ \\ ${ }^{1}$ Khoa Luật, Đại học Quốc gia Hà Nội, 144 Xuân Thủy, Cầu Giấy, Hà Nội, Việt Nam \\ ${ }^{2}$ Học viện Chính sách và Phát triển, ngõ 7 Tôn Thất Thuyết, Cầu Giấy, Hà Nội, Việt Nam \\ Nhận ngày 11 tháng 04 năm 2019 \\ Chỉnh sửa ngày 22 tháng 5 năm 2019; Chấp nhận đăng ngày 24 tháng 6 năm 2019
}

\begin{abstract}
Tóm tắt: Trong một thị trường cạnh tranh, người tiêu dùng được bảo vệ bởi pháp luật nhằm ngăn ngừa những rủi ro, thiệt hại do những bất cân xứng về vị thế giữa bên bán và người tiêu dùng, hay còn biết đến tới khái niệm "người tiêu dùng yếu thế". Pháp luật bảo vệ quyền lợi người tiêu dùng của Đài Loan (Trung Quốc) và Việt Nam đều tạo các cơ sở pháp lí cần thiết để người tiêu dùng có thể vận dụng trong suốt quá trình tiêu dùng và ngay cả khi phát sinh thiệt hại, rủi ro. Những kinh nghiệm lập pháp và kết quả thực thi quy định của Đài Loan cũng là bài học quan trọng cho Việt Nam khi hoàn thiện pháp luật tiêu dùng.
\end{abstract}

Tù khóa: Đài Loan, luật bảo vệ người tiêu dùng, yếu thế.

\section{Đặt vấn đề}

Pháp luật bảo vệ quyền lợi người tiêu dùng được hình thành là sự "bù đắp" cho bên yếu thể trong quan hệ hợp đồng tiêu dùng hàng hóa, dịch vụ. Hướng tới một mục đích quan trọng là bảo vệ quyền lợi chính đáng của người tiêu dùng và tái lập sự cân bằng trong quan hệ hợp đồng tiêu dùng, những lí thuyết pháp lí dân sự được đề cập và phản ánh trong quy định pháp luật của nhiều quốc gia, trong đó có pháp luật Việt Nam và pháp luật Đài Loan (Trung Quốc). Trước yêu cầu cải cách và hoàn thiện pháp luật tiêu dùng, pháp luật Đài Loan với kinh nghiệm xây dựng từ rất sớm là bài học quan trọng cho nhà lập pháp Việt Nam sau gần 10 năm thực thi Luật bảo vệ quyền lợi người tiêu dùng.

\section{Khái niệm "người tiêu dùng yếu thế" trong quan hệ tiêu dùng}

Mặc dù, Tổ chức Giáo dục, khoa học và văn hóa Liên hợp quốc UNESCO từng phân tích: "Tính dễ bị tổn thương là một phần của điều kiện của con người; một số người có thể nói rằng

\footnotetext{
* Tác giả liên hệ.

Địa chỉ email: dieptrongnguyenvnu@gmail.com

https://doi.org/10.25073/2588-1167/vnuls.4220
} 
những tổn thương đó khiến chúng ta 'con người' hơn. Không ai là không bị tổn thương...”[1]. Điều này cho thấy bất cứ chủ thể nào không chỉ riêng người tiêu dùng trong quan hệ tiêu dùng đều phải đối mặt với những rủi ro bị tổn thương. Nhu cầu bảo vệ bên yếu thế trong quan hệ hợp đồng xuất hiện từ khi khái niệm "hợp đồng" chính thức được quy định trong luật pháp thời kỳ La Mã. Ví dụ, nguyên tắc thiện chí bona fides của Tòa án; cơ chế exception doli để giải phóng nghĩa vụ cho con nợ hay các quy định bảo vệ phụ nữ và trẻ em trong Luật 12 bảng... Trong pháp luật hiện đại, mỗi chủ thể trong các quan hệ pháp luật khác nhau sẽ được đặc trưng bởi những rủi ro bị tổn thương khác nhau, và người tiêu dùng là một chủ thể như vậy. Khái niệm "nhóm yếu thế" (tiếng anh: Disadvantaged groups) thường được sử dụng để nói về một nhóm người đặc trưng bởi những rủi ro cao hơn về sự nghèo đói, loại trừ khỏi xã hội, sự phân biệt và bị bạo lực hơn so với cư dân bình thường khác. "Nhóm yếu thế" trong luật quốc tế bao gồm nhưng không giới hạn tới những dân tộc thiểu số, người di cư, người khuyết tật, người bị cách ly khỏi xã hội và trẻ em [2]. Tuy nhiên, so sánh với những rủi ro pháp lí mà người tiêu dùng phải đối diện khi tham gia quan hệ tiêu dùng, Dennis E. Garrett và Peter G. Toumanoff đã đặt ra một câu hỏi về vấn đề này, rằng: "Liệu người tiêu dùng có phải là một nhóm yếu thế và dễ bị tổn thương" [3]. Câu hỏi này đã được Tổ chức Consumer Affairs Victoria (Autralia) trả lời khi đưa ra định nghĩa về "Người tiêu dùng yếu thế" được hiểu là "những người có thể dễ dàng hoặc nhanh chóng bị thiệt hại trong quá trình tiêu dùng, tính dễ bị tổn thương phát sinh từ những đặc điểm của thị trường đối với một sản phẩm cụ thể, hoặc các thuộc tính hoặc hoàn cảnh của cá nhân đó khi quyết định tiêu dùng hoặc việc theo đuổi biện pháp khắc phục cho bất kỳ thiệt hại nào họ phải chịu, hoặc sự kết hợp của những điều này"’[4].

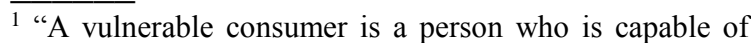
readily or quickly suffering detriment in the process of consumption. A susceptibility to detriment may arise from either the characteristics of the market for a particular product, the product's qualities or the nature of the transaction; or the individual's attributes or circumstances which adversely affect consumer decision-making or the
}

Tính yếu thế của người tiêu dùng được phản ánh thông qua 02 thành tố gồm: (1) Khả năng được bảo vệ và bảo đảm trước những nguy cơ rủi ro và thiệt hại; (2) Khả năng đương đầu với những hệ quả tiêu cực khi phát sinh rủi ro và thiệt hại. Các nghiên cứu cũng cho thấy tính yếu thế và dễ bị tổn thương là một khái niệm "động” khi nó có thể thay đổi phụ thuộc vào hoàn cảnh cụ thể trong suốt quá trình tiêu dùng, trong đó yếu tố pháp lí là một trong những nhân tố quyết định. Cũng vì lí do này mà pháp luật các quốc gia trên thế giới và phán quyết của Tòa Công lý Châu Âu ${ }^{2}$ cũng chỉ ghi nhận thông lệ khái niệm "người tiêu dùng cá nhân" (mà không phải là tổ chức) nhằm "khu biệt hóa" đối tượng được bảo vệ, tập trung nguồn lực bảo vệ nhóm người tiêu dùng yếu thế [5].

Giữa pháp luật bảo vệ quyền lợi người tiêu dùng của Đài Loan và Việt Nam, cũng như quan niệm chung được thừa nhận trong pháp luật tiêu dùng nhiều quốc gia, "người tiêu dùng" được hiểu thống nhất tại Khoản 2 Điều 2 Luật tiêu dùng Đài Loan và Khoản 1 Điều 3 Luật tiêu dùng Việt Nam, là người mua hàng hóa hoặc sử dụng dịch vụ cuối cùng trong quan hệ tiêu dùng, hay nói cách khác, người tiêu dùng là người thụ hưởng cuối cùng giá trị hàng hóa. Từ quá trình lựa chọn sản phẩm, quyết định mua, tiêu dùng và hậu tiêu dùng, người tiêu dùng luôn phải đối diện với những rủi ro có thể gây thiệt hại tới quyền và lợi ích hợp pháp nếu như Nhà nước và pháp luật không can thiệp. Lí thuyết về bất cân xứng thông tin ("information asymmetry") giữa bên bán (nhà cung cấp) và bên mua (người tiêu dùng) đã được khẳng định trong nhiều nghiên cứu khi lí thuyết lí tưởng về quan hệ tiêu dùng cân bằng thông tin giữa hai chủ thể này hiếm khi có được trong thực tế [6]. Thực tiễn đã chỉ ra rằng trong quan hệ hợp đồng tiêu dùng, bên yếu thế thông thường là người tiêu dùng. Mặc dù có thể đủ năng lực hành

pursuit of redress for any detriment suffered; or a combination of these".

2 Criminal Proceedings against Patrice Di Pinto, Case C$361 / 89$ [1991] I-1189 (cited in Geraint Howells and Stephen Weatherill, Consumer Protection Law, 2nd ed. (England: Ashgate Publishing Limited, 2005) at 365. 
vi khi xác lập giao dịch nhưng "sự yếu thế" được phản ánh thông qua khả năng hạn chế khi tiếp cận, xử lí, hiểu các thông tin về hàng hóa, dịch vụ và giao dịch; hạn chế trong đàm phán; hạn chế về tiềm lực tài chính, địa vị xã hội và khả năng theo đuổi các công cụ giải quyết tranh chấp.

Như vậy, "người tiêu dùng yếu thế" được điều chỉnh trong pháp luật tiêu dùng của Việt Nam và Đài Loan là người tiêu thụ hàng hóa, sử dụng dịch vụ cuối cùng trong chuỗi luân chuyển của hàng hóa, là chủ thể dễ dàng hoặc có nguy cơ bị thiệt hại, rủi ro lợi ích nhiều hơn trong quan hệ tiêu dùng do những bất lợi về thông tin, năng lực và vị thế.

\section{Khả năng được bảo vệ và bảo đảm trước khi phát sinh rủi ro}

Dựa trên các 08 nhóm quyền cơ bản của người tiêu dùng trong Hướng dẫn bảo vệ người tiêu dùng của Liên hợp quốc năm 1985 [7], Luật pháp các quốc gia trong đó có Đài Loan và Việt Nam đều đảm bảo và xây dựng những năng lực pháp lí ban đầu để bảo vệ và bảo đảm quyền lợi cho "người tiêu dùng yếu thế" trước khi rủi ro, thiệt hại phát sinh. Điều 3 Luật tiêu dùng Đài Loan năm 1994, sửa đổi mới nhất năm 2005 (sau đây gọi chung là Luật tiêu dùng Đài Loan) đặt ra nguyển tắc đối với người bán hàng hóa phải có nghĩa vụ bảo đảm: chất lượng, an toàn, vệ sinh, yêu cầu ngăn chặn những rủi ro, thiệt hại về tính mạng, cơ thể, sức khỏe, tài sản và những loại ích khác của người tiêu dùng; nghĩa vụ đáp ứng yêu cầu pháp luật về quảng cáo, dán nhãn, đóng gói [8]. Theo pháp luật Việt Nam, ngoài việc quy định nghĩa vụ của người bán, dựa trên hệ thống quyền của người tiêu dùng quy định trong Hướng dẫn của Liên Hợp quốc về bảo vệ người tiêu dùng ban hành năm 1985, sửa đổi năm 1999 được CI (Consumers International), Luật năm 2010 của Việt Nam cũng ghi nhận 08 nhóm quyền cơ bản cho người tiêu dùng gồm: được

\footnotetext{
$\overline{3}$ Điều 8 Luật Bảo vệ quyền lợi người tiêu dùng Việt Nam năm 2010.

${ }^{4}$ Điều 66 Nghị định số 185/2013/NĐ-CP ngày 15/11/2013 của Chính phủ Việt Nam quy định xử phạt vi phạm hành
}

bảo đảm an toàn; được cung cấp thông tin; được lựa chọn hàng hoá, dịch vụ; được góp ý kiến với tổ chức, cá nhân kinh doanh hàng hóa, dịch vụ; được tham gia xây dựng và thực thi chính sách; được yêu cầu bồi thường thiệt hại; được khiếu nại, tố cáo và được tư vấn, hỗ trợ, hướng dẫn kiến thức về tiêu dùng ${ }^{3}[9]$. Từ các quy định này, người tiêu dùng được bảo vệ thông qua các nghĩa vụ của người bán trong quá trình cung ứng hàng hóa, dịch vụ. Đơn cử:

- Nghĩa vu đối với bao gói sản phẩm, hàng hóa: Điều 7 Luật tiêu dùng Đài Loan quy định nghĩa vụ thông tin của nhà sản xuất - kinh doanh trên bao gói sản phẩm trong trường hợp hàng hóa hoặc dịch vụ gây nguy hại đến tính mạng, cơ thể, sức khỏe hoặc tài sản của người tiêu dùng, một cảnh báo và phương pháp đối phó trong trường hợp khẩn cấp đối với những nguy hiểm đó phải được ghi tại một vị trí thích hợp. Pháp luật Việt Nam cũng quy định nghĩa vụ này của người bán tại Khoản 1 Điều 12 Luật BVNTD năm 2010 và quy định về dán nhãn sản phẩm, hàng hóa tại Nghị định 43/2017/NĐ-CP ngày 14/4/2017 của Chính phủ Việt Nam [10]. Ngoài ra, hành vi vi phạm về cung cấp thông tin cảnh báo đầy đủ về hàng hóa, dịch vụ có thể bị xử phạt hành chính tới cao nhất là 50 triệu đồng Việt Nam và có thể bị tước giấy phép kinh doanh tới 06 tháng ${ }^{4}[11]$.

- Nghĩa vu thu hồi hàng hóa: thực tế cho thấy nghĩa vụ thu hồi hàng hóa khuyết tật là một nội dung đặc biệt quan trọng trong pháp luật tiêu dùng nhiều quốc gia. Điều 10 Luật tiêu dùng Đài Loan làm rõ nghĩa vụ này bắt buộc phải thực hiện khi doanh nghiệp có "nghi ngờ" về hàng hóa hoặc dịch vụ có rủi ro gây nguy hiểm đến an toàn và sức khỏe người tiêu dùng. Điều 22 Luật BVNTD Việt Nam có quy định tương tự về trách nhiệm thu hồi hàng hóa có khuyết tật, đồng thời bổ sung nghĩa vụ thông báo công khai việc thu hồi hàng hóa trong ít nhất 05 số báo liên tiếp hoặc 05 ngày liên tiếp trên đài phát thanh, truyền hình địa phương.

chính trong hoạt động thương mại, sản xuất, buôn bán hàng giả, hàng cấm và bảo vệ quyền lợi người tiêu dùng. 
- Trách nhiệm dân sư của doanh nghiệp: Luật tiêu dùng Đài Loan luôn đặt ra vấn đề trách nhiệm liên đới và riêng rẽ giữa các doanh nghiệp phân phối, bán hàng, thiết kế, sản xuất, chế tạo trong nghĩa vụ thông tin, cảnh báo rủi ro cho người tiêu dùng. Quyền lợi của người tiêu dùng được bảo đảm ngay tại thời điểm mua hàng khi nghĩa vụ cảnh báo và chứng minh phù hợp các quy chuẩn, tiêu chuẩn và tính an toàn. Nghĩa vụ liên đới và riêng rẽ tiếp tục được quy định bắt buộc đối với các doanh nghiệp phân phối hoặc bán hàng, doanh nghiệp thiết kế, sản xuất hoặc chế tạo hàng hóa dịch vụ tại Điều 8 và tương tự đối với doanh nghiệp nhập khẩu hàng hóa tại Điều 9. Ở Việt Nam, trách nhiệm này giới hạn ở trách nhiệm riêng rẽ của chủ thể bán hàng, còn chỉ phát sinh trách nhiệm liên đới với bên thứ ba trong thiệt hại từ cung cấp thông tin không chính xác và không đầy đủ ${ }^{5}$.

- Giải thich hợp đồng tiêu dùng: với quan điểm tương đồng về tính bất cân xứng về vị thế giữa người tiêu dùng và bên bán, Luật tiêu dùng Đài Loan quy định về việc giải thích Điều khoản và Điều kiện của hợp đồng tiêu dùng hàng loạt (hay Luật tiêu dùng Việt Nam gọi tên là hợp đồng mẫu) phải được giải thích theo hướng có lợi cho người tiêu dùng, áp dụng nguyên tắc bình đẳng và có đi có lại (Điều 11). Việc giải thích có lợi không đồng nghĩa với việc tước bỏ quyền được đảm bảo một thời hạn hợp lí để xem xét nội dung hợp đồng cũng như hệ quả hủy bỏ hợp đồng nếu như quyền này không được doanh nghiệp bảo đảm.

- Hệ quả vô hiệu hợp đồng tiêu dùng: vô hiệu là hệ quả tất yếu nếu như quá trình giao kết hợp đồng giữa doanh nghiệp và người tiêu dùng không bảo đảm rằng "người tiêu dùng yếu thế" được đối xử công bằng hơn trong quan hệ mua bán. Điều 12 Luật tiêu dùng Đài Loan đặt ra trường hợp "không công bằng" để áp dụng vô hiệu giao dịch mua bán giữa người tiêu dùng và doanh nghiệp. Trong đó, Khoản 1 Điều 12 cho thấy sự "không công bằng" sẽ dẫn tới vô hiệu khi giữa người tiêu dùng và bên bán không đạt được

\footnotetext{
${ }^{5}$ Điểm c Khoản 1 Điều 13 Luật BVQLNTD Việt Nam năm 2010.
}

sự "bình đẳng". Hợp đồng vô hiệu còn được đặt ra tại Điều 17 Luật tiêu dùng Đài Loan khi doanh nghiệp bỏ qua nghĩa vụ công khái các Điều khoản bắt buộc và Điều khoản bị cấm trong hợp đồng hàng loạt, dẫn tới tính trạng rủi ro về thông tin cho người tiêu dùng. Đối với phương thức thư mời mua hoặc bán hàng tận cửa, bất cứ thỏa thuận nào vi phạm nghĩa vụ thông tin của bên bán cũng như tạo ra một trạng thái "không sẵn lòng" của người tiêu dùng khi mua hàng hoặc một thỏa thuận bồi hoàn sản phẩm nếu chẩm dứt hợp đồng "kém thuận lợi" cho người tiêu dùng thì đều áp dụng vô hiệu theo Điều 18 Luật tiêu dùng Đài Loan. Trong pháp luật tiêu dùng Việt Nam và rộng hơn là pháp luật dân sự, một trong các căn cứ vô hiệu hợp đồng là tồn tại và chứng minh được sự lừa dối, đe dọa, cưỡng ép ý chí khi giao kết. Sự cưỡng ép ý chí này trở nên khá "mơ hồ" nếu như quan hệ mua bán giữa người tiêu dùng và bên bán được xác lập nhanh chóng và mang tính đơn lẻ. Việc quy định rõ ràng một cơ sở về "không sẵn lòng" là một điều đặc biệt quan trọng giúp "người tiêu dùng yếu thế" luôn chủ động trong quan hệ mua bán và từ đó nâng cao trách nhiệm của bên bán trong việc tạo ra sự hài lòng và thỏa mãn từ người mua.

\section{Khả năng ứng phó với những hệ quả tiêu cực}

Những hệ quả tiêu cực như thiệt hại vật chất (sức khỏe, tính mạng, tài sản) hay tinh thần đặt ra khi hàng hóa, dịch vụ khuyết tật gây ra đòi hỏi phải tồn tại những cơ sở pháp lí để truy cứu trách nhiệm bồi thường đối với doanh nghiệp. Trách nhiệm này bao gồm các nghĩa vụ của doanh nghiệp đối với thiệt hại và xử lí một vụ việc tranh chấp khi phát sinh.

Nghĩa vu của doanh nghiẹp khi phát sinh nguy hại cho người tiêu dùng

Luật tiêu dùng Đài Loan cho thấy quan điểm xây dựng trách nhiệm nghiêm ngặt (strict liability) đối với doanh nghiệp khi cung ứng sản phẩm tới người tiêu dùng. Khi phát sinh thiệt hại, việc giải thích có lợi cho người tiêu dùng và trách 
nhiệm của các doanh nghiệp là 02 điều kiện bắt buộc, ngay kể cả khi doanh nghiệp chứng minh được mình không có lỗi đối với sai sót đó. Điều 7 Luật tiêu dùng Đài Loan quy định nghĩa vụ liên đới hoặc riêng rẽ của các doanh nghiệp kinh doanh khi việc cảnh báo không đảm bảo và gây thiệt hại, đồng thời việc xem xét giảm nhẹ trách nhiệm chỉ đặt ra khi các doanh nghiệp chứng minh được rằng họ không có lỗi đối với sai sót đó. Điều này có vẻ thiếu công bằng cho các doanh nghiệp, nhưng lại hợp lí bởi nó ràng buộc các doanh nghiệp phải nỗ lực cảnh báo các rủi ro có thể xảy ra cho người tiêu dùng trong mọi trường hợp và tự nâng cao trách nhiệm xã hội của họ.

Điều này Luật tiêu dùng Việt Nam chưa làm được khi các nghĩa vụ của doanh nghiệp mới chỉ dừng lại ở quy định nghĩa vụ cảnh báo mà không ghi nhận trách nhiệm và giải thích tình huống phát sinh thiệt hại. Tuy nhiên, Luật BVNTD năm 2010 của Việt Nam đưa vào áp dụng một nguyên tắc đặc biệt trong giải quyết tranh chấp tiêu dùng tại Tòa án, đó là "người mua có nghĩa vụ cung cấp chứng cứ và chứng minh thiệt hại của mình, và người bán có nghĩa vụ chứng minh mình không có lỗi gây ra thiệt hại"'.

Thực thi quyền xủ lí khiếu nại tiêu dùng

Nếu như Luật tiêu dùng Việt Nam chỉ ghi nhận khiếu nại tiêu dùng như một trình tự hành chính trong giải quyết tranh chấp tiêu dùng và giao cho các tổ chức bảo vệ quyền lợi người tiêu dùng và cơ quan bảo vệ quyền lợi người tiêu dùng của Chính phủ tự xây dựng quy trình và thời hạn xử lí thì Luật tiêu dùng Đài Loan ấn định thời hạn tối đa của doanh nghiệp là 15 ngày để giải quyết khiếu nại và trường hợp không thực hiện thì cơ quan thanh tra tiêu dùng sẽ can thiệp ngay sau đó để bảo đảm quyền lợi cho người tiêu dùng. Luật BVNTD Việt Nam đang bỏ ngỏ quy định về thời hạn giải quyết khiếu nại này. Hiện nay, Cục Cạnh tranh và bảo vệ người tiêu dùng thuộc Bộ Công Thương Việt Nam đang triển khai song song 03 phương thức tiếp nhận khiếu nại tiêu dùng gồm: trực tuyến (qua website hoặc

\footnotetext{
$\overline{{ }^{6} \text { Điều } 42}$ Luật BVNTD Việt Nam năm 2010.
}

email); bưu điện và trực tiếp. Trong đó, khiếu nại qua email chiếm tới $76 \%$, việc xử lí khiếu nại thành công chiếm $97 \%$.

Sự can thiẹp của cơ quan bảo vệ người tiêu dùng và chính quyền địa phương

Việc can thiệp của chính quyền địa phương tại Đài Loan trong việc xử lí các vụ việc liên quan tới hàng hóa khuyết tật gây thiệt hại được hậu thuẫn đáng kể bởi các quy định của Luật tiêu dùng Đài Loan. Theo đó, Luật cho phép từ chính quyền cấp huyện đã được trao thẩm quyền để có thể can thiệp một cách hiệu quả vào quá trình thiết kế, sản xuất, chế tạo, gia công, nhập khẩu, phân phối hàng hóa bị nghi ngờ đe dọa đến tính mạng, sức khỏe và tài sản của người tiêu dùng (Điều 36 Luật tiêu dùng Đài Loan). Biện pháp mạnh nhất có thể được cơ quan này và các cơ quan cấp cao hơn thực hiện là tạm ngừng và ngừng hoạt động cung ứng đồng thời có thể áp dụng bổ sung các biện pháp khác nếu thấy cần thiết. Ở tầm chính sách, Viện Hành chính Đài Loan và một cơ quan liên bộ là Ủy ban bảo vệ người tiêu dùng là những cơ quan tư vấn, xây dựng và kiến nghị chính sách bảo vệ người tiêu dùng.

Khi phát sinh các khiếu nại tiêu dùng cần hòa giải, Luật tiêu dùng Đài Loan cho phép chính quyền cấp huyện và cấp tỉnh có thẩm quyền xem xét thành lập Hội đồng hòa giải tranh chấp với sự tham gia của các đại diện chính quyền, thanh tra tiêu dùng, nhóm bảo vệ người tiêu dùng, đại diện hiệp hội ngành nghề để đảm bảo tiếng nói công bằng cho các nhóm lợi ích trong quan hệ tiêu dùng. Điều này cũng là một hạn chế trong pháp luật tiêu dùng Việt Nam khi Luật tiêu dùng năm 2010 của Việt Nam mới đề cập tới hòa giải tranh chấp tiêu dùng như một cơ chế chính thức được nhắc tới nhưng không có hướng dẫn cụ thể về thực hiện. Năm 2017, Chính phủ Việt Nam có ban hành Nghị định số 22/2017/NĐ-CP về hòa giải thương mại như một hướng dẫn pháp lí ban đầu để giải quyết tranh chấp tiêu dùng theo hình thức này nhưng khó phát huy hiệu quả bởi " tranh

\footnotetext{
${ }^{7}$ Nguồn: Cục Cạnh tranh \& Bảo vệ người tiêu dùng - Bộ Công Thương Việt Nam, số liệu 06 tháng đầu năm 2018.
} 
chấp tiêu dùng” thực chất không hề tương đồng với "tranh chấp thương mại".

Nhũng yêu cầu đặc biệt đối với vu kiện tiêu dùng

"Người tiêu dùng yếu thế" được bảo đảm về quyền lợi khá rõ ràng trong cả pháp luật tiêu dùng Đài Loan và Việt Nam thông qua các co chế khá khác biệt. Điều 48 Luật tiêu dùng Đài Loan hướng tới xây dựng những thẩm phán chuyên trách đối với các vụ kiện tiêu dùng - một điều mà Việt Nam chưa làm được, thì Điều 41 Luật tiêu dùng Việt Nam lại xây dựng được một mô hình rút gọn lí tưởng với mục tiêu giải quyết nhanh chóng các vụ kiện tiêu dùng đơn giản có mức ngạch thấp dưới 100 triệu đồng Việt Nam. Pháp luật tiêu dùng Đài Loan và Việt Nam gặp nhau ở quy định về quyền khởi kiện tập thể của nhóm chủ thể đại diện quyền lợi người tiêu dùng. Năm 2015, ở Bến Tre - Việt Nam, 34 người tiêu dùng gửi đơn khiếu nại Hội bảo vệ người tiêu dùng tỉnh về bánh mỳ ngộ độc của Cơ sở bánh mỳ Minh Tuyến, TP Bến Tre từ năm 2013. Mất 02 năm, 02 vụ kiện, xử 02 cấp sơ thẩm và phúc thẩm, vụ kiện mới khép lại với nghĩa vụ bồi thường tổng số tiền 22 triệu đồng của bị đơn chủ cơ sở bánh mỳ theo kết quả hòa giải ${ }^{8}$. Tương tự là vụ việc anh Vũ Song Toàn mất xe tại nhà hàng My Way và yêu cầu nhà hàng bồi thường, từ năm 2011 tới nay vẫn chưa có kết quả9 ${ }^{9}$ Từ đó cho thấy, thực tiễn xét xử vụ án vi phạm quyền lợi người tiêu dùng ở Việt Nam thường kéo dài và là nguyên nhân khiến người tiêu dùng có tâm lí ngại khởi kiện và khiếu nại.

Bên cạnh đó, một quy định đặc biệt quan trọng là nghĩa vụ bồi thường và quyền yêu cầu bồi thường thì Luật tiêu dùng Đài Loan đã mở ra một cơ chế đòi bồi thường ưu tiên cho người tiêu dùng khi mức yêu cầu đòi bồi thường có thể lên tới gấp 03 lần mức thiệt hại thực tế nếu như liên quan tới yếu kém của doanh nghiệp hoặc một hành vi cố ý (Điều 51). Trong khi đó, Luật tiêu

\footnotetext{
${ }^{8}$ Các bản án: Bản án sơ thẩm số 08/2015/DS-ST ngày 09/2/2015; Bản án sơ thẩm số 11/2015/DS-ST ngày 04/3/2015 của Tòa án nhân dân TP Bến Tre; Biên bản hòa giải ngày 17/8/2015 giữa 17 nguyên đơn và bà Võ Thị Minh Tuyến.
}

dùng Việt Nam và Bộ luật dân sự Việt Nam năm 2015 chỉ quy định về nghĩa vụ bồi thường thiệt hại dựa trên thiệt hại thực tế chứng minh được.

\section{Kết luận}

"Người tiêu dùng yếu thế" là một khái niệm được sinh ra từ việc xem xét vị thế của người tiêu dùng trong quan hệ với bên bán trong một quan hệ mua bán vốn dĩ dựa trên nguyên tắc bình đẳng. Tuy nhiên, sự yếu thế của người tiêu dùng trong thực tiễn giao dịch lại đi ngược lại nguyên tắc bính đẳng đó của dân sự, đòi hỏi pháp luật các quốc gia cần có những quy định và cách giải thích, vận dụng pháp luật nhằm lấy lại sự cân bằng này. Pháp luật tiêu dùng Đài Loan qua nhiều năm thực thi đã cho thấy một thực tế rằng pháp luật cần có những quy định mạnh mẽ và thể hiện rõ ràng quan điểm bảo vệ "người tiêu dùng yếu thế". Pháp luật tiêu dùng Việt Nam sau gần 10 năm thực thi cũng cần nghiên cứu quan điểm lập pháp này để có những sửa đổi cần thiết để tăng hiệu quả thực thi. Kết quả tranh chấp tiêu dùng ở Việt Nam qua các năm phản ánh rằng các quy định hiện hành chưa tạo ra sự khác biệt, chưa đủ thu hút người tiêu dùng vận dụng để bảo vệ quyền lợi cho mình.

\section{Tài liệu tham khảo}

[1] United Nations Educational, Scientific and Cultural Organization, The principle of respect for human vulnerability and personal integrity - report of the International bioethics committee of UNESCO, UNESCO, 2013.

[2] Eige Experts - Eige Europa, CSW Agreed conclusions on the elimination and prevention of all forms of violence against women and girls, para. 34, (2013), E/2013/27-E/CN.6/2013/11.

\footnotetext{
${ }^{9}$ Các bản án: Bản án sơ thẩm số 06/2012/DS-ST ngày 10/5/2012 của Tòa án nhân dân quận Cầu Giấy; Bản án phúc thẩm số 180/2012/DS-PT ngày 11/10/2012 của Tòa án nhân dân TP Hà Nội; Thông báo số 1568/TB-TDS ngày 20/12/2012 của Tòa dân sự - Tòa án nhân dân tối cao về việc tiếp nhận đơn đề nghị giám đốc thẩm.
} 
[3] Dennis E. Garrett và Peter G. Toumanoff (2010), Are consumers disadvantaged or vulnerable? An examination of consumer complaints to the better business bureau, The Journal of Consumer Affairs, vol.44, No.1 (2010) 3-23.

[4] Consumer Affairs Victoria, What do we mean by 'vulnerable' and 'disadvantaged' consumers, Discussion paper, 2004.

[5] Nguyễn Văn Cương, Nguyễn Thị Vân Anh, Giáo trình Luật Bảo vệ quyền lợi người tiêu dùng, $\mathrm{NXB}$ Chính trị Quốc gia Sự Thật, 2012.

[6] Bairagya Ramsundar \& Sarkar Shubhabrata, Information Asymmetry - Consumer behavior and market equilibrium, Euro-Asian Journal of Economics and Finance, vol.1, Issue 1 (11/2013) p.33-40.
[7] United Nations, Guidelines for Consumer protection, 1985.

[8] Luật tiêu dùng Đài Loan năm 1994, sửa đổi năm 2005.

[9] Luật Bảo vệ quyền lợi người tiêu dùng Việt Nam năm 2010.

[10] Nghị định số 43/2017/NĐ-CP ngày 14/4/2017 của Chính phủ Việt Nam về nhãn hàng hóa.

[11] Nghị định số 185/2013/NĐ-CP ngày 15/11/2013 của Chính phủ Việt Nam quy định xử phạt vi phạm hành chính trong hoạt động thương mại, sản xuất, buôn bán hàng giả, hàng cấm và bảo vệ quyền lợi người tiêu dùng. 